\title{
Rice field drainage affects nitrogen dynamics and management
}

by Bruce A. Linquist, Kaden Koffler, Jim E. Hill and Chris van Kessel

Many California rice growers are now using foliar-active herbicides that require fields to be drained before application. Current regulations limit aerial herbicides and they must be applied by ground, requiring a soil surface dry enough to support application equipment. Our research showed that draining rice fields for a prolonged period early in the season led to a buildup of nitrate in the soil. About $60 \%$ of this nitrogen was lost when the field was reflooded, reducing nitrogen-use efficiency and uptake, and lowering grain yields. Nitrate-nitrogen accumulated at a rate of about 1.8 pounds per acre daily, and accumulation began about 4 days after the field was drained. During a typical drain of 10 to 14 days, about 20 pounds of nitrate-nitrogen per acre can be lost. Field experiments showed that incorporating fertilizer nitrogen into the subsurface soil increases nitrogen-use efficiency. Based on this research, we recommend that growers incorporate as much of their preplant nitrogen as possible below the soil surface and limit the drain period as much as possible.

A critical challenge facing California rice growers is managing herbicide-resistant weeds, which can inflict major yield losses and lead to exorbitant herbicide costs. The evolution of herbicide resistance, combined with increased restrictions on how and which herbicides are applied, has limited the effectiveness of traditional weed-control strategies. Consequently, many growers are using foliar-active herbicides, which require that rice fields be drained

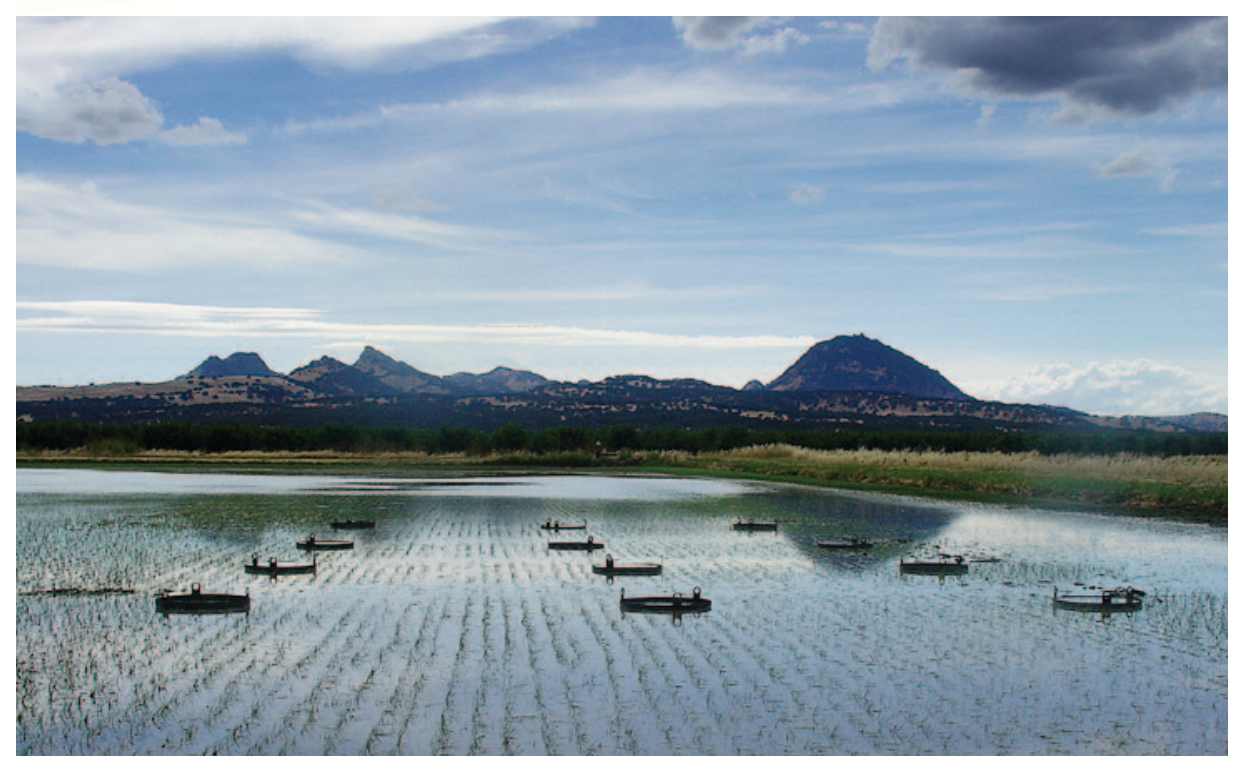

Rice growers now drain fields early in the season to apply herbicides by ground, rather than by air. The impacts of this change on nitrogen management in rice are not well understood. Above, metal rings were used to evaluate nitrogen dynamics in flooded and nonflooded fields.

to expose the weeds before application (foliar-active herbicides must have adequate leaf surface area in order to be absorbed by the plant). Furthermore, regulations limit aerial applications of these foliar-active herbicides to prevent spray drift to sensitive crops.

In the past, herbicides were flown on and into flooded rice fields. Growers now apply a substantial portion of herbicides by ground, which requires that the soil surface be dry enough to support application equipment, increasing the length of time that the field is drained. The drainage period usually begins within 2 weeks of rice planting and can last up to 3 weeks, depending on how the grower plans to apply the herbicide, the soil type and climatic conditions such as wind and temperature.

This change in early-season water management has direct implications for nitrogen fertility management, but current recommendations were developed for continuously flooded rice. The impacts of an early-season drain on nitrogen fertilizer dynamics, particularly the effect on potential nitrogen losses, are not well understood. Of all nutrients applied as fertilizer, nitrogen is required by rice in higher quantities and is most susceptible to losses (Schnier 1995).
Fertilizer nitrogen is applied to rice fields in the form of ammonium $\left(\mathrm{NH}_{4}\right)$ or urea (which rapidly converts to ammonium). When a rice field is flooded, the fertilizer largely remains as ammonium (Linquist et al. 2006) and is taken up as ammonium by the rice plant.

When the field is drained and the soil becomes aerobic, ammonium is oxidized through microbial processes (known as nitrification) into nitrate $\left(\mathrm{NO}_{3}\right)$. Nitrate is susceptible to losses in rice systems, and it disappears from the rice rooting zone within a week or two of a soil being flooded (Linquist et al. 2006). The fate of nitrate in flooded soils is difficult to determine. Plants, including rice, can take up nitrate before it is lost by other means. The most likely cause of nitrate loss from California rice systems is denitrification. When the field is reflooded and the soil becomes anaerobic, microbes convert a portion of the nitrate into nitrogen gas (denitrification), which is lost to the atmosphere (Buresh and De Datta 1991). In some rice systems, nitrate leaching can be a significant loss (Yoon et al. 2006; Zhu et al. 2000); in California, however, rice soils are very impermeable, and under such conditions it is likely that soil nitrate denitrifies before it leaches (Bowman et al. 2002). 
that these nutrients were not limiting. All fields were flooded for planting immediately after the preplant nitrogen applications.

\section{Fate of nitrate}

Linquist et al. (2006) reported that shortly after flooding for planting, most nitrate is lost from the soil plow layer, and most mineral nitrogen is in the form of ammonium. The nitrate present prior to flooding the fields for planting would most likely have been lost via denitrification (Buresh and De Datta 1991). Therefore, before the fields in this study were drained for the herbicide application, the soil mineral nitrogen would have been predominantly ammonium. Total soil mineral nitrogen was highly variable among fields and years, and ranged from approximately 40 to 185 pounds per acre (fig. 1). High variability is expected since most fertilizer nitrogen is banded below the soil surface. When soils are sampled, it is not possible to know if the samples are taken from within a band or between bands. Over time, however, this nitrogen moves laterally through the soil (Obcema et al. 1984), and subsurface nitrogen levels become less variable.

At the end of the drain period, the form of soil mineral nitrogen differed significantly between the drained and undrained treatments. By the end of the 10- or 11-day drain period, there was less than 1 pound nitrate-nitrogen $\left(\mathrm{NO}_{3}-\mathrm{N}\right)$ per acre in the undrained treatment, but a significant amount of nitrate had accumulated in the drained treatment (fig. 1). In 2006, 31 pounds nitrate-nitrogen per acre accumulated in the straw-incorporated field and 25 pounds accumulated in the strawburned field during the 11-day drain period. In 2007, 4 and 18 pounds nitratenitrogen per acre had accumulated in the straw-incorporated and burned fields, respectively. In 2007, we attribute the low nitrate accumulation during the drain period in the incorporated field to less soil drying relative to other treatments (based on soil moisture measurements).

Of primary interest in this study is the fate of nitrate that had accumulated in the drained treatment during the drain period. Was it taken up by the plant or lost? At harvest there were significant differences in crop nitrogen uptake between the two water-management treatments. In 2006 and 2007, total nitrogen uptake in the undrained treatment of both fields was 15 and 12 pounds per acre higher on average than in the drained treatment, respectively (fig. 2). Soil nitrate accumulation averaged 25 pounds per acre in the drained treatment, and plant nitrogen uptake was 14 pounds per acre less than in the undrained treatment. This suggests that approximately $60 \%$ of the nitrate was not taken up by the crop but was

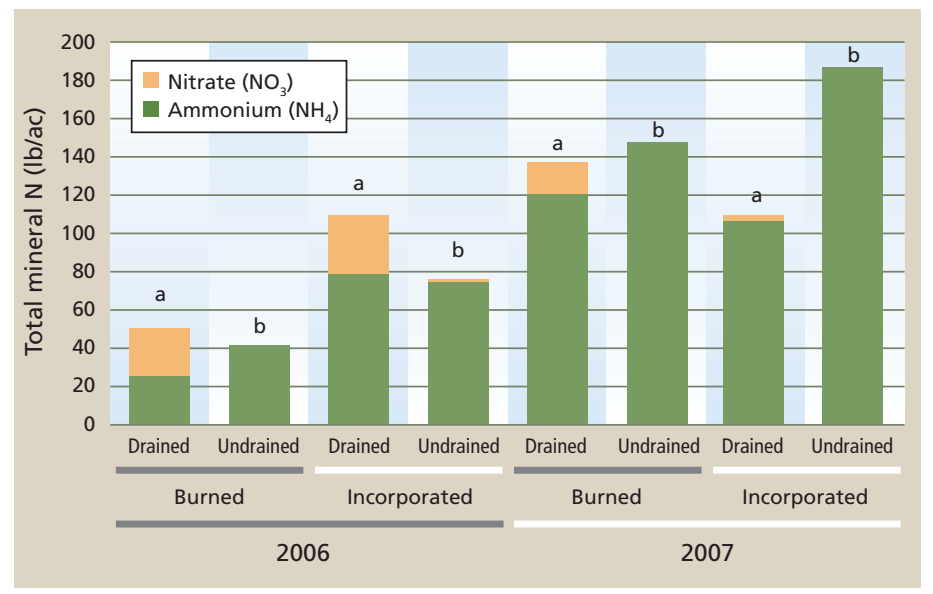

Fig. 1. Nitrate $\left(\mathrm{NO}_{3}\right)$ and ammonium $\left(\mathrm{NH}_{4}\right)$ in soils in undrained and drained treatments. Soil samples were taken at the end of the 10- or 11-day drain period from the 0 - to 6 -inch topsoil layer. Different letters above each pair of bars indicate significantly different nitrate values $(P<0.05)$. lost. We surmise that the reduced nitrogen uptake was due to nitrogen losses via denitrification, since losses through leaching and surface runoff are believed to be minimal (Zhao et al. 2009).

In the burned fields in both 2006 and 2007, lower nitrogen uptake in the drained treatment resulted in lower grain yields (on average 680 pounds per acre; $P<0.07$ ) relative to the undrained treatment (fig. 2). In the straw-incorporated fields, grain yields were similar between the drained and undrained treatments. Soil nitrogen is higher in soils where straw is incorporated compared to where straw is burned (Linquist et al. 2006; Eagle et al. 2000). Therefore, in the strawincorporated fields, even though nitrogen uptake was less in the drained treatment in 2006, the crop yields were not compromised.

These studies indicate that prolonged draining of rice fields early in the growing season promotes nitrification. Nitrate that accumulates during this period is then subject to losses, which results in reduced nitrogen uptake and

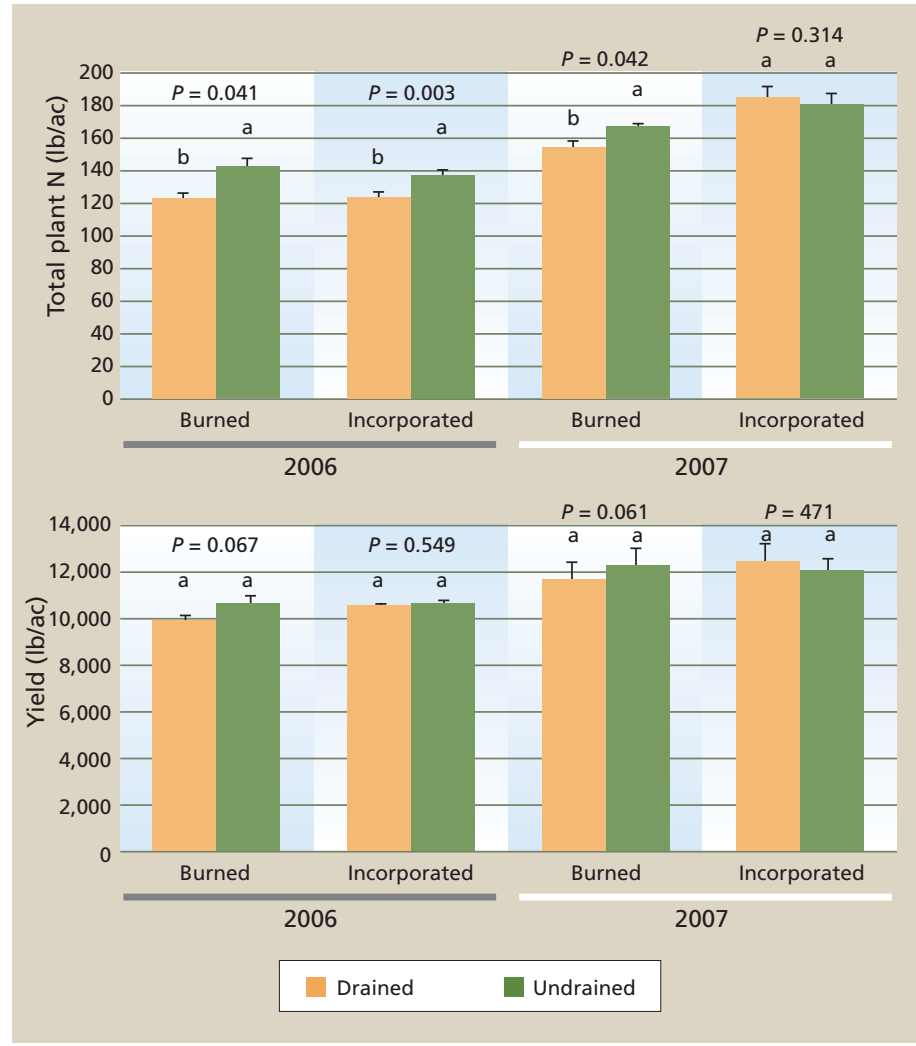

Fig. 2. Total plant nitrogen uptake and rice yields ( $14 \%$ moisture) in 2006 and 2007 from treatment rings that had been drained or undrained earlier in the season. Different letters above a pair of bars indicate significantly different values $(P<0.05)$. 
potentially lower yields. Two questions arise: How can we predict the amount of nitrogen that is lost, and how can we manage fertilizer nitrogen to reduce such losses?

\section{Soil nitrate accumulation}

To predict how much nitrogen is potentially lost, we conducted a study across the Sacramento Valley region with the primary objective of quantifying soil nitrate accumulation rates during the drain period. We identified 22 rice fields where an early-season drain for an herbicide application was part of the weed management strategy. Soils were sampled from 0 to 6 inches every 3 or 4 days during the critical flooddrain-reflood phase to monitor changes in soil nitrogen status in all fields. Soil mineral nitrogen was extracted with 2-molar potassium chloride immediately after taking the soil sample, then analyzed for nitrate and ammonium. Bulk density of the soil was determined for each field. For analysis, the drainage period was standardized across fields - the first drain day was when the field had drained to no more than puddling on the soil surface and the soils were saturated with water.

In all fields, nitrate accumulated during the drain period and declined after reflooding (fig. 3), as observed in the ring study. There was a high degree of variation across fields in both the rate and total amount of nitrate accumulated. The high variability among fields may be due to some soils being less prone to drying, different fertilizer rates and management strategies used by growers, and temperature differences. Higher temperatures favor nitrification (Breuer et al. 2002), and it is likely that earlier-planted fields experienced lower daily temperatures than those planted later in the season.

When analyzed across sites, however, we found a significant correlation between the number of days a field had been drained and the amount of nitrate in the field (fig. 4). The linear regression equation indicates that nitrate increased at a rate of 1.8 pounds nitrate-nitrogen per acre per day. This value provides an approximate rule of thumb that growers can use to decide how much nitrogen to apply to make up for what was lost or became unavailable to the crop.

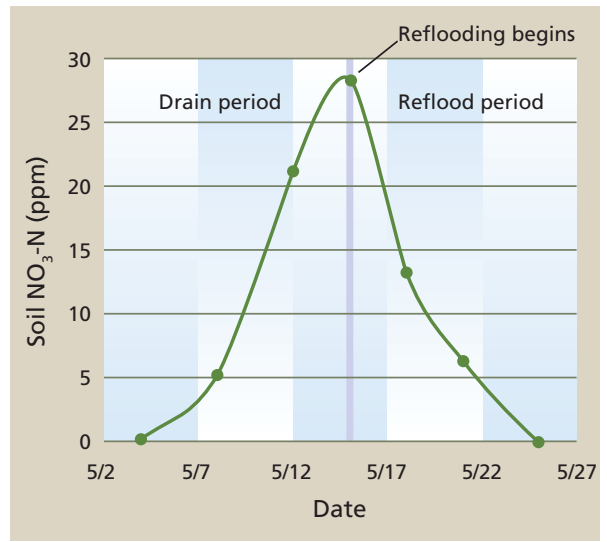

Fig. 3. Soil nitrate-nitrogen $\left(\mathrm{NO}_{3}-\mathrm{N}\right)$ during an early-season drainage period and subsequent reflooding period for one of 22 fields (Abel Road, Colusa) examined in 2007.

Interestingly, and likely because soils remain saturated for a period of time after draining, nitrate did not start to accumulate until the fourth day after the drain. Therefore, draining water for a short period (less than 4 days) of time for herbicide applications or other management practices results in little to no risk of nitrate-nitrogen losses.

\section{Nitrogen fertilizer management}

Our results indicate the large potential for nitrogen losses in rice systems where an early-season drain is part of the weed management practice. Improved nitrogen management practices require changes in the timing or placement of nitrogen fertilizer to achieve acceptable nitrogen-use efficiency. We predict that surface-applied nitrogen is more susceptible to nitrification (and subsequently denitrification) than subsurface-applied nitrogen, since the surface soil remains aerobic for a longer period. If this is indeed the case, growers should apply fertilizer nitrogen below the soil surface (as aquaammonia) as much as possible.

To test this hypothesis, two field studies were conducted in 2006 and 2008 near Sheridan (Placer County) and Biggs (Butte County), respectively, on fields drained for an extended period early in the season. In these field trials, three fertilizer-nitrogen treatments were evaluated. With the exception of a no-nitrogen fertilizer control, similar amounts of nitrogen were applied in the treatments within each site (185 to 189 pounds per acre in Sheridan and 120

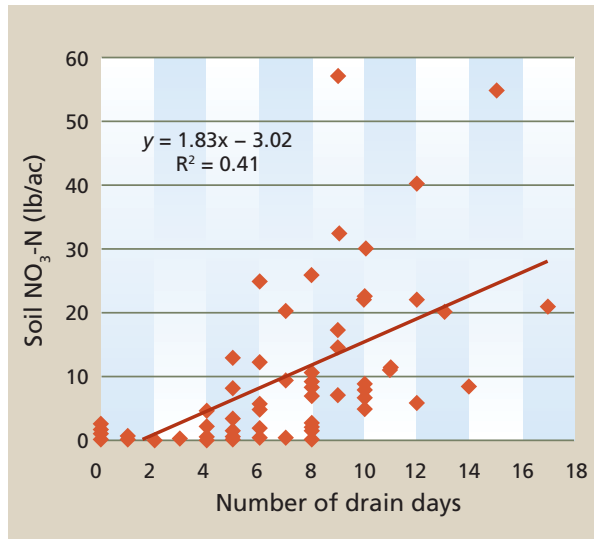

Fig. 4. Soil nitrate-nitrogen $\left(\mathrm{NO}_{3}-\mathrm{N}\right)$ as a function of the number of days a field is drained. Data is from 22 rice fields sampled every 3 or 4 days during 2007 drainage period.

pounds per acre in Biggs), but the fertilizer treatments differed in timing and placement.

The treatments were (1) no nitrogen, (2) all preplant nitrogen fertilizer applied as aqua-ammonia to a depth of 3 to 4 inches (all subsurface) and (3) the conventional practice, where a portion of the preplant nitrogen was applied as aqua-ammonia and the remainder to the surface (subsurface plus surface) (table 2). At the Sheridan site, the grower also applied 42 pounds nitrogen per acre to the subsurface and subsurface plus surface treatments just after reflooding. The no-nitrogen treatment soil was covered with a tarp and did not receive nitrogen fertilizer. Treatments were replicated three times. The subsurface nitrogen was applied by the grower as aqua-ammonia to a depth of 3 to 4 inches using commercial equipment. All surface nitrogen was applied as urea by hand. The drain period in each field began 23 and 5 days after planting, and fields were reflooded 15 and 11 days later at Sheridan and Biggs, respectively. At harvest the plots were sampled for total aboveground biomass and yield. Grain and straw samples were analyzed for nitrogen to determine uptake in each treatment.

In both locations, when no nitrogen was applied, yields ranged from 3,500 to 3,700 pounds per acre, and there was a significant response to applied nitrogen (table 2). At both sites the highest yield and nitrogen uptake were in the treatment where all of the nitrogen fertilizer was applied preplant as 


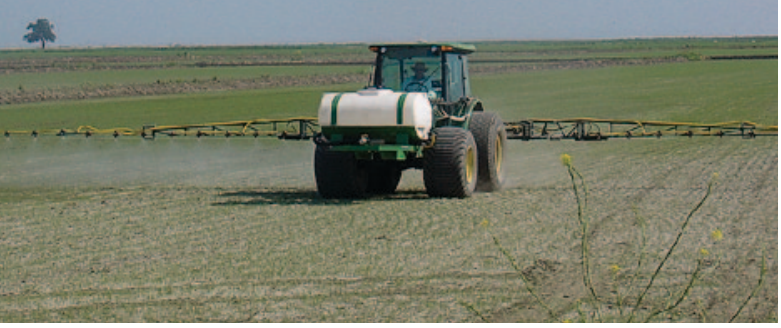

A rice grower applies herbicide to a drieddown field. Drained fields must be dry enough to support application equipment with large tires, which can take 2 to 3 weeks.

aqua-ammonia. Averaged across both sites, the all-subsurface treatment had higher fertilizer nitrogen-use efficiency, $59 \%$, compared to $49 \%$ in the subsurface plus surface treatment. These results support our hypothesis that surfaceapplied fertilizer nitrogen is more susceptible to losses than nitrogen that is placed below the soil surface.

Consequently, our recommendation is to apply as much total nitrogen as possible as aqua-ammonia injected 3 or 4 inches below the soil surface. This is the same recommendation made by Linquist et al. (2009) for conventionally managed fields with no earlyseason drain. Their 3-year study on 12 California rice fields, varying in straw and water management, found that incorporating all nitrogen fertilizer below the soil surface resulted in improved yields and nitrogen-use efficiency, regardless of water management practices. Surface-applied nitrogen was used less efficiently, even when rice fields were continuously flooded. Others have reported similar findings (Mikkelsen and Finfrock 1957; Broadbent and Mikkelsen 1968; Obcema et al. 1984).

\section{References}

Bowman BAM, Castaneda AR, Bhuiyan SI. 2002. Nitrate and pesticide contamination of groundwater under rice-based cropping systems: Past and current evidence from the Philippines. Agric Ecosyst Env 92:185-99.

Breuer L, Kiese R, Butterbach-Bahl K. 2002. Temperature and moisture effects on nitrification rates in tropical rain-forest soils. Soil Sci Soc Am J 66:834-44. Broadbent FE, Mikkelsen DS. 1968. Influence of placement on uptake of tagged nitrogen by rice. Agron J 60:674-7.

Buresh RJ, De Datta SK. 1991. Nitrogen dynamics and management in rice-legume cropping systems. Adv Agron 45:1-59.

Doane TA, Horwath WR. 2003. Spectrophotometric determination of nitrate with a single reagent. Anal Lett 36:2713-22.

\section{Maximizing efficiency and yield}

Draining rice fields for a prolonged period early in the season led to a buildup of nitrate in the soil. About $60 \%$ of this nitrate-nitrogen was subsequently lost when the field was reflooded, reducing nitrogen-use efficiency and uptake, and reducing grain yields. Nitrate accumulation begins about 4 days after the field has been drained and accumulates at a rate of about 1.8 pounds per acre daily. During a typical drain of about 10 to 14 days, this translates into an accumulation of roughly 20 pounds nitrate-nitrogen per acre. Field experiments supported the idea that incorporating fertilizer nitrogen into the soil (as growers routinely do for continuously flooded rice) increases nitrogen-use efficiency. Based

on this research, we recommend that growers incorporate as much of their preplant nitrogen as possible below the soil surface, as aqua-ammonia. Furthermore, growers should limit the duration of the drain period as much as possible, since subsurface-applied nitrogen fertilizer remains susceptible to nitrogen losses when soils dry and become aerobic.

\begin{abstract}
B.A. Linquist is Professional Researcher, K. Koffler is Graduate Student, and J.E. Hill is Cooperative Extension Specialist and Associate Dean for International Programs, College of Agricultural and Environmental Sciences, UC Davis; and C. van Kessel is Professor and Chair, Department of Plant Sciences, UC Davis. The authors thank the many collaborating rice growers and the California Rice Research Board for funding this research.
\end{abstract}

TABLE 2. Fertilizer nitrogen $(\mathrm{N})$ rate and timing treatments, and their effects on rice yield (14\% moisture) and total nitrogen uptake in two field experiments, 2006 and 2008

\begin{tabular}{|c|c|c|c|c|c|c|}
\hline $\begin{array}{l}\text { Treatment } \\
\text { designation }\end{array}$ & $\begin{array}{c}\text { Preplant } \\
\text { subsurface* }\end{array}$ & $\begin{array}{l}\text { Preplant } \\
\text { surface }\end{array}$ & $\begin{array}{l}\text { Postdrain } \\
\text { topdress }\end{array}$ & Total applied & Grain yield & Total uptake \\
\hline & $\ldots \ldots \ldots \ldots$ & $\cdots \cdots / b$ & cre....... & $\ldots \ldots \ldots$ & Ib/acre & Ib N/acre \\
\hline \multicolumn{7}{|l|}{2006 (Sheridan) } \\
\hline No nitrogen & 0 & 0 & 0 & 0 & $3,544 \mathrm{bt}$ & $53 c \neq$ \\
\hline $\begin{array}{l}\text { Subsurface + } \\
\text { surface }\end{array}$ & 113 & 34 & 42 & 189 & $10,325 a$ & $149 b$ \\
\hline All subsurface & 143 & 0 & 42 & 185 & $10,653 a$ & $163 a$ \\
\hline \multicolumn{7}{|l|}{2008 (Biggs) } \\
\hline No nitrogen & 0 & 0 & 0 & 0 & $3,715 b$ & $55 c$ \\
\hline $\begin{array}{l}\text { Subsurface + } \\
\text { surface }\end{array}$ & 80 & 40 & 0 & 120 & $9,801 \mathrm{a}$ & $109 b$ \\
\hline All subsurface & 120 & 0 & 0 & 120 & $10,904 a$ & $125 a$ \\
\hline \multicolumn{7}{|c|}{$\begin{array}{l}\text { * Preplant subsurface nitrogen applied by grower as aqua-ammonia. } \\
\text { † Yields followed by the same letter within the same site-year indicate no difference between treatments }(P<0.05) \text {. } \\
\text { ₹ Total nitrogen uptake values followed by the same letter within the same site-year indicate no difference between } \\
\text { treatments; } P<0.05 \text { for } 2006 \text { (Sheridan) and } P<0.06 \text { for } 2008 \text { (Biggs). }\end{array}$} \\
\hline
\end{tabular}

Eagle AJ, Bird JA, Horwath WR, et al. 2000. Rice yield and nitrogen utilization efficiency under alternative straw management practices. Agron J 92:1096-103. Forster J. 1995. Soil nitrogen. In: Nannipieri P (ed.) Methods in Applied Soil Microbiology and Biochemistry. San Diego, CA: Acad Pr. p 79-87.

Linquist BA, Brouder SM, Hill JE. 2006. Winter straw and water management effects on soil nitrogen dynamics in California rice systems. Agron J 98:1050-9.

Linquist BA, Hill JE, Mutters RG, et al. 2009. Assessing the necessity of surface applied pre-plant nitrogen fertilizer in rice systems. Agron J 101:906-15.

Mikkelsen DS, Finfrock DC. 1957. Availability of ammoniacal nitrogen to lowland rice as influenced by fertilizer placement. Agron J 49:296-300.

Obcema WN, De Datta SK, Broadbent FE. 1984.

Movement and distribution of fertilizer nitrogen as affected by depth of placement in wetland rice. Fert Res $5: 125-48$.
Patrick Jr WH, Reddy KR. 1976. Fate of fertilizer nitrogen in a flooded rice soil. Soil Sci Soc Am J 40:678-81.

Schnier HF. 1995. Significance of timing and method of $\mathrm{N}$ fertilizer application for the $\mathrm{N}$-use efficiency in flooded tropical rice. Fert Res 42:129-38.

Yoon KS, Choi JK, Son JG, Cho JY. 2006. Concentration profile of nitrogen and phosphorus in leachate of a paddy plot during the rice cultivation period in southern Korea. Comm Soil Sci Plant Anal 37:1957-72.

Zhao $X$, Xie YX, Xiong ZQ, et al. 2009. Nitrogen fate and environmental consequence in paddy soil under rice-wheat rotation in the Taihu lake region, China. Plant Soil 319:225-34.

Zhu JG, Han Y, Liu G, et al. 2000. Nitrogen in percolation water in paddy fields with a rice/wheat rotation. Nut Cyc Agroeco 57:75-82. 